\title{
Penentuan Premi Asuransi Jiwa Gabungan Dwiguna dengan Asumsi Mortalita Gompertz dan Pengaruh Nilai Tukar terhadap Tingkat Bunga
}

\author{
Khoiroh Alfiana $^{1 *}$, Ade Ima Afifa Himayati ${ }^{2}$ \\ ${ }^{1,2}$ Universitas Muhammdiyah Kudus \\ *khoiroh alfiana@umkudus.ac.id
}

\begin{abstract}
ABSTRAK
Penelitian ini berfokus pada pembahasan mengenai perhitungan premi asuransi jiwa gabungan dwiguna. Asuransi jiwa gabungan dwiguna memberikan dua manfaat sekaligus yaitu manfaat diberikan jika salah satu tertanggung meninggal dunia atau memberikan manfaat jika kedua tertanggung masih hidup hingga akhir masa kontrak asuransi. Perhitungan premi asuransi jiwa gabungan dwiguna ini melibatkan asumsi Gompertz pada probabilitas hidup dan pengaruh nilai tukar pada tingkat bunga. Perhitungan premi dihitung berdasarkan asumsi mortalita Gompertz, yang mempengaruhi probabilitas hidup tertanggung status gabungan. Selain itu, adanya pengaruh fluktuasi dollar terhadap tingkat bunga yang berdampak pada nilai premi asuransi. Berdasarkan hasil yang diperoleh, turunnya nilai tukar rupiah mengakibatkan tingkat bunga meningkat jika dibandingkan dengan tingkat bunga acuhan. Sehingga, dapat disimpulkan nilai premi asuransi dipengaruhi nilai tukar. Hal ini berakibat adanya peningkatan risiko yang dialami perusahaan asuransi.
\end{abstract}

Kata kunci: asuransi jiwa gabungan dwiguna, hukum mortalita Gompertz, nilai tukar.

\section{ABSTRACT}

This paper focused on calculation of premiums of n-years endowmnet insurance for joint life status. Endowment joint life insurance gives two benefits, benefits is paid if the first dead occurs or the two insured survives at the end of $n$ years term insurance policy. The calculation of premiums based on Gompertz mortality assumptions that effect the probability of joint life insured. In addition, the calculation of premiums also refered by interest rate which influenced the exchange rate. Based on the calculation results, fluctuations of exchange rate effected the interst rate. The greater of depreciation of foreign exchange rate made interst rate increased. As the result, concluded that the $n$-years endowment joint life insurance follows the fluctuations of the exchange rate. This could be increasing risk for insurance company.

Keywords: endowment joint-life status, Gompertz's law, exchange rate. 


\section{PENDAHULUAN}

Asuransi jiwa merupakan jaminan risiko terhadap jiwa seorang yang dipertanggungkan. Ada dua jenis asuransi jiwa di Indonesia yaitu asuransi jiwa perseorangan (single-life) dan asuransi jiwa kelompok (multiple-life) yang melibatkan dua orang tertanggung atau lebih. Asuransi jiwa gabungan (joint-life) merupakan salah satu jenis dari asuransi kelompok. Asuransi jenis ini biasanya diikuti dua individu atau pasangan suami istri yang bertujuan sebagai bentuk perlindungan masa tua jika salah satu meninggal, dimana manfaat diberikan saat ada kematian pertama terjadi (Bowers et al., 1990).

Referensi mengenai teori asuransi jiwa gabungan antara lain Bowers (1991), Promislow (2011), dan Sertdemir (2013). Penelitian lebih lanjut, perhitungan nilai aktuaria berdasarkan hukum mortalita Gompertz dapat menggunakan pendekatan kontinu dari percepatan mortalita (force of mortality) (Yang and Zhou, 2003) sehingga memudahkan dalam perhitungan. Distribusi Gompertz pertama kali didefinisikan oleh B. Gompertz pada tahun 1825, yang digunakan untuk menentukan percepatan mortalita. Namun dalam perkembangannya, asumsi Gompertz digunakan untuk menentukan probabilitas hidup dan probabilitas kematian.

Pada penelitian ini, difokuskan pada asuransi gabungan dwiguna (endowment) yaitu asuransi jiwa gabungan yang memberikan manfaat dua manfaat sekaligus yaitu memberikan manfaat jika terjadi kematian pertama dari salah satu tertanggung dalam masa kontrak atau memberikan manfaat apabila kedua tertanggung tetap hidup pada akhir masa asuransi. Pada pembahasan ini, probabilitas hidup kedua tertanggung dianggap saling independen. Perhitungan probabilitas hidup didasarkan pada asumsi mortalita Gompertz dan dengan menggunakan data Tabel Mortalita Indonesia tahun 2011. Nilai anuitas jiwa asuransi jiwa gabungan dwiguna dihitung dengan tingkat bunga yang berubah mengikuti fluktuasi nilai tukar asing. Perhitungan tingkat bunga yang dipengaruhi nilai tukar rupiah terhadap dollar diharapkan dapat mengikuti tren ekonomi dunia (Zayanti, Kresnawati, dan Megah, 2019).

Pembahasan berupa perhitungan tingkat diskon faktor yang dipengaruhi adanya fluktuasi nilai tukar asing, dengan menghitung arus dan volatilitas nilai tukar. Selanjutnya, perhitungan probabilitas hidup dengan mengikuti asumsi mortalita Gompertz yang digunakan untuk perhitungan nilai sekarang aktuaria dan nilai anuitas, selain itu ditambahkan adanya pengaruh nilai tukar terhadap diskon faktor yang diperoleh dalam perhitungan nilai anuitas jiwa. Hasil akhir berupa analisis pengaruh nilai tukar terhadap premi tahunan asuransi jiwa gabungan dwiguna. Perhitungan premi ini diharapkan dapat mengikuti tren ekonomi dunia, berdasarkan volatilitas nilai tukar asing terhadap tingkat bunga sehingga dapat mengukur tingkat risiko yang dialami perusahan jika terjadi lonjakan nilai tukar asing. Perhitungan dilakukan dengan menggunakan Excel.

\section{METODE}

Penelitian ini membahas mengenai perhitungan nilai premi tahunan dari asuransi jiwa gabungan dwiguna dengan menggunakan metode eksperimental. Penelitian menggunakan ilustrasi kasus polis asuransi jiwa yang melibatkan dua tertanggung, dimana manfaat dibayarkan jika salah satu dari tertanggung meninggal. Langkah yang diperlukan dalam menghitung besar premi asuransi jiwa gabungan dwiguna dengan probabilitas kematian 
gabungan mengikuti asumsi mortalita Gompertz dan laju bunga dipengaruhi fluktuasi dollar adalah (1) menentukan diskon faktor $v$ yang dipengaruhi nilai tukar dengan menghitung arus (drift) dan volatilitas (volatility) fluktuasi rupiah terhadap dollar; (2) menghitung probabilitas kematian dari tertanggung dibawah asumsi mortalita Gompertz, dengan menghitung estimasi parameter Gompertz; (3) menentukan nilai sekarang bersih aktuaria asuransi jiwa gabungan dwiguna untuk $n$ tahun; (4) menentukan anuitas jiwa dengan asumsi mortalita Gompertz dan pengaruh nilai tukar terhadap tingkat bunga; dan (5) menentukan premi tahunan asuransi jiwa gabungan dwiguna.

\subsection{Tingkat Bunga yang Dipengaruhi Nilai Tukar}

Berdasarkan data kurs dollar yang diperoleh dari www.bi.go.id, nilai drift $\mu$ dan volatilitas $\sigma$ sebagai berikut (Zayanti, Kresnawati and Megah, 2019).

$$
\begin{gathered}
\mu=2\left(\ln (E(X))-\frac{1}{2} \ln \left(E\left(X^{2}\right)\right)\right) \\
\sigma=\left[\ln \left(E\left(X^{2}\right)\right)-2 \ln (E(X))\right]
\end{gathered}
$$

Sedemikian hingga, diskon faktor berdasarkan pengaruh fluktuasi dollar dinyatakan

$$
v^{t}=\exp \left(-\left(\delta-\mu-\frac{1}{2} \sigma^{2}\right)(t)\right)
$$

Untuk $t=1$, diskon faktor $v=\exp \left(-\left(\delta-\mu-\frac{1}{2} \sigma^{2}\right)\right)$.

\subsection{Hukum Mortalita Gompertz}

Distribusi Gompertz $G(x \mid \mu, \sigma)$ dengan rata-rata $\mu$ dan standar deviasi $\sigma$ didefinisikan sebagai (Willemse and Koppelaar, 2000)

$$
G(x \mid \mu, \sigma)=W\left(\frac{x-a}{b}\right)
$$

dengan $W(x)=1-e^{-e^{x}}$ dan konstanta $a$ dan $b$ memenuhi

$$
\sigma=\frac{\pi}{\sqrt{6}} b \text { dan } \mu=a-b \gamma
$$

dan $\gamma$ konstanta Euler-Mascheroni.

Distribusi $G(x \mid \mu, \sigma)$ dikatakan Gompertz karena

$$
G(x \mid \mu, \sigma)=1-g^{c^{x}}
$$

saat

$$
g=e^{-\frac{-a}{b}} \text { dan } c=e^{\frac{1}{b}}
$$

Percepatan mortalita untuk grup mengikuti hukum Gompertz didefinisikan dengan (Yang and Zhou, 2003)

$$
\mu(x)=B c^{x}
$$

dengan $B>0$ dan $c>1$.

Berdasarkan persamaan (8), probabilitas hidup seorang berusia $x$ hingga $t$ tahun dan probabilitas seorang berusia hingga $(x+t)$ dinyatakan sebagai

$$
\begin{gathered}
{ }_{t} p_{x}=g^{c^{c^{x}\left(c^{t}-1\right)}} \\
{ }_{t} q_{x}=1-g^{c^{x}\left(c^{t}-1\right)}
\end{gathered}
$$




\subsection{Nilai Sekarang Aktuaria Asuransi Jiwa Gabungan Dwiguna (Endowment) di Bawah Asumsi Gompertz}

Nilai sekarang aktuaria atau biasa disebut premi tunggal bersih dari asuransi jiwa gabungan dwiguna seorang berusia $x$ dan $y$ dalam jangka waktu perlindungan $n$ tahun adalah

$$
A_{x y: \bar{n} \mid}=\sum_{k=0}^{n-1} v^{k+1}{ }_{k} p_{x y} q_{x+k: y+k}+v_{n}^{n} p_{x y}
$$

Berdasarkan asumsi mortalita Gompertz, premi tunggal bersih dinyatakan dengan

$$
A_{x y: \bar{n} \mid}=\sum_{k=0}^{n-1} v^{k+1}\left(g^{\left(c^{x}+c^{y}\right)\left(c^{k}-1\right)}-g^{\left(c^{x}+c^{y}\right)\left(c^{k+1}-1\right)}\right)+v^{n} g^{\left(c^{x}+c^{y}\right)\left(c^{n}-1\right)}
$$

\subsection{Anuitas Jiwa dengan Tingkat Bunga yang Dipengaruhi Nilai Tukar}

Nilai anuitas jiwa asuransi gabungan dwiguna dari usia $x$ dan $y$ adalah (Sertdemir, 2013)

$$
\ddot{a}_{x y \cdot \bar{n} \mid}=\sum_{k=0}^{n-1} v^{k}{ }_{k} p_{x y}
$$

dengan probabilitas hidup status gabungan mengikuti asumsi Gompertz, anuitas jiwa gabungan dari seorang berusia $\mathrm{x}$ dan $\mathrm{y}$ dinyatakan dengan

$$
\ddot{a}_{x y: \bar{n} \mid}=\sum_{k=0}^{n-1} v^{k} g^{\left(c^{x}+c^{y}\right)\left(c^{k}-1\right)}
$$

Dengan adanya pengaruh fluktuasi dollar dari (3), anuitas jiwa menjadi

$$
\ddot{a}_{x y \cdot \bar{n} \mid}=\sum_{k=0}^{n-1} \exp \left[-\left(\delta-\mu-\frac{1}{2} \sigma^{2}\right) k\right] g^{\left(c^{x}+c^{y}\right)\left(c^{k}-1\right)}
$$

\section{HASIL DAN PEMBAHASAN}

\subsection{Pengaruh Nilai Tukar terhadap Tingkat Bunga}

Berdasarkan data kurs dollar dari tahun 2015 hingga 2020 yang diperoleh dari www.bi.go.id_berikut.

\section{Kurs Dollar}

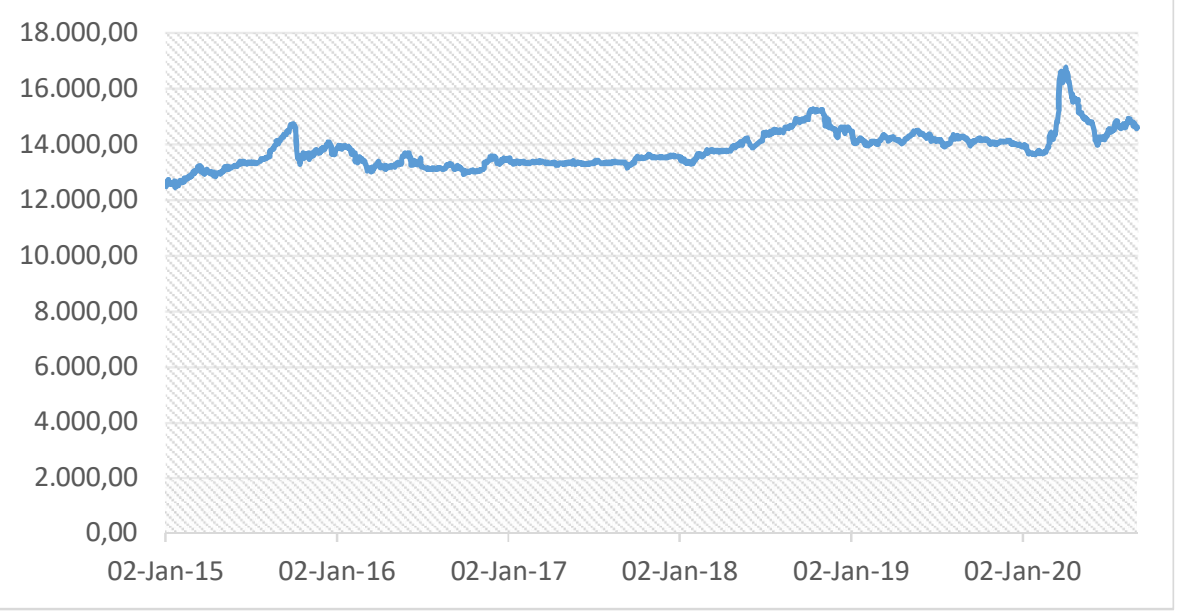

Gambar 1. Kurs Dollar Tahun 2015-2020 
Diperoleh besar drift $\mu=-0.002246782$ kurang dari 0 menunjukkan bahwa rupiah melemah terhadap dollar, terlebih disaat adanya pandemi saat ini-Sept 2020. Sedangkan volatilitasnya menunjukkkan fluktuasi dollar sebesar 0.047400231.

Diasumsikan tingkat bunga yang digunakan mengikuti BI-rate yang ditetapkan Bank Indonesia untuk bulan Juli 2020 yaitu 4\%, diperoleh laju tingkat bunga $\delta=\ln (1+i)=$ 0.0392207132 . Sedemikian hingga, diskon faktor berdasarkan pengaruh fluktuasi dollar untuk $t=1$, diskon faktor $v=0.960458884$.

\subsection{Premium}

Misalkan pasangan suami (40 tahun) dan istri (35 tahun) membeli polis asuransi jiwa gabungan dwiguna 10 tahun. Manfaat akan diberikan pada saat salah satu meninggal. Berdasarkan data Tabel Mortalita Indonesia 2011, diperoleh $c=1.040447$ dan $B=$ 0.002465. Sehingga, probabilitas status jiwa gabungan untuk usia (40) dan (35) disajikan dalam tabel berikut.

Tabel 1. Probabilitas Status Jiwa Gabungan dengan Asumsi Gompertz

\begin{tabular}{lrr}
\hline $\boldsymbol{k}$ & ${ }_{k} p_{40}$ & ${ }_{k} p_{35}$ \\
\hline 0 & 1 & 1 \\
1 & 0.987792 & 0.989977 \\
2 & 0.975249 & 0.979654 \\
3 & 0.962367 & 0.969029 \\
4 & 0.949145 & 0.958096 \\
5 & 0.935581 & 0.946851 \\
6 & 0.921673 & 0.935292 \\
7 & 0.907423 & 0.923416 \\
8 & 0.89283 & 0.911219 \\
9 & 0.877897 & 0.898699 \\
\hline
\end{tabular}

Premi asuransi jiwa gabungan dwiguna dinyatakan sebagai (Sertdemir, 2013)

$$
P_{x y: \bar{n} \mid}=\frac{A_{x y: \bar{n} \mid}}{\ddot{a}_{x y: \bar{n} \mid}}
$$

dengan mensubtitusikan persamaan (12) dan (15), diperoleh Premi tahunan asuransi jiwa gabungan dwiguna dengan asumsi mortalita Gompertz dan pengaruh nilai tukar terhadap tingkat bunga sebagai berikut.

$$
P_{x y: \bar{n} \mid}=\frac{A_{x y \cdot \bar{n} \mid}=\sum_{k=0}^{n-1} v^{k+1}\left(g^{\left(c^{x}+c^{y}\right)\left(c^{k}-1\right)}-g^{\left(c^{x}+c^{y}\right)\left(c^{k+1}-1\right)}\right)+v^{n} g^{\left(c^{x}+c^{y}\right)\left(c^{n}-1\right)}}{\ddot{a}_{x y: \bar{n} \mid}=\sum_{k=0}^{n-1} \exp \left[-\left(\delta-\mu-\frac{1}{2} \sigma^{2}\right) k\right] g^{\left(c^{x}+c^{y}\right)\left(c^{k}-1\right)}}
$$

Sehingga, premi tahunan asuransi jiwa gabungan untuk usia (40) dan (35) disajikan dalam Tabel 2 berikut. 
Tabel 2. Nilai Aktuaria dan Anuitas Jiwa Gabungan

\begin{tabular}{rrrr}
\hline $\boldsymbol{k}$ & ${ }_{k} p_{40: 35}$ & \multicolumn{1}{c}{$A_{40: 35: 1 \overline{0} \mid}$} & \multicolumn{1}{c}{$\ddot{a}_{40: 355: \overline{0} \mid}$} \\
\hline 0 & 1 & 0.537498 & 0.9593805 \\
1 & 0.977891 & 0.556557 & 0.9508318 \\
2 & 0.955407 & 0.573519 & 0.9419753 \\
3 & 0.932561 & 0.588484 & 0.9328057 \\
4 & 0.909372 & 0.601555 & 0.9233181 \\
5 & 0.885856 & 0.61283 & 0.9135076 \\
6 & 0.862034 & 0.622408 & 0.9033699 \\
7 & 0.837929 & 0.630388 & 0.892901 \\
8 & 0.813564 & 0.636867 & 0.8820973 \\
9 & 0.788965 & 0.641941 & 0.8709559 \\
\hline
\end{tabular}

Berdasarkan Tabel 2 dan Persamaan (17), dengan manfaat sebesar 1 diperoleh premi tahunan asuransi jiwa gabungan sebesar 0.654449. Sedangkan premi tahunan asuransi jiwa gabungan tanpa pengaruh fluktuasi nilai tukar untuk manfaat sebesar 1 adalah 0.614388. Jika dibandingkan dengan premi asuransi jiwa gabungan tanpa adanya pengaruh nilai tukar terhadap tingkat bunga tersebut, maka asuransi jiwa gabungan dwiguna dengan asumsi gompertz dan pengaruh nilai tukar terhadap tingkat bunga cenderung menghasilkan nilai premi tahunan yang lebih besar. Hal ini dikarenakan adanya fluksuasi nilai tukar yang mengakibatkan tingkat bunga lebih besar jika dibandingkan tingkat bunga acuhan.

\section{SIMPULAN}

Premi tahunan dipengaruhi oleh probabilitas hidup, tingkat suku bunga dan biaya-biaya lainnya. Berdasarkan hasil pembahasan, probabilitas hidup di bawah asumsi gompertz lebih kecil jika dibandingkan dengan data probabilitas hidup dari tabel Mortalita Indonesia 2011. Hal ini memberikan dampak adanya perbedaan nilai premi asuransi jiwa gabungan dwiguna. Selain itu, adanya pengaruh nilai tukar terhadap tingkat bunga juga mempengaruhi nilai anuitas jiwa asuransi gabungan. Depresiasi pada nilai tukar asing mengakibatkan fluktuasi pada tingkat bunga, yang berdampak pada nilai premi asuransi. Saat nilai tukar asing turun maka tingkat bunga meningkat dan sebaliknya. Hal ini akan meningkatkan risiko bagi perusahaan asuransi. Untuk penelitian selanjutnya, dapat dikembangkan pengaruh-pengaruh ekonomi lainnya dalam perhitungan premi asuransi sehingga diharapkan dapat memberikan premi yang menyesuaikan dengan pertumbuhan ekonomi dunia. Selain itu, penilitiaan terhadap probabilitas mortalita juga dapat dikembangkan mengikuti asumsi mortalita yang lain.

\section{DAFTAR PUSTAKA}

Andiraja, N. and Fadli, A. (2015) 'Nilai Akumulasi Anuitas Berjangka Dengan Distribusi Makeham Pada Status Hidup Gabungan', Jurnal Sains Matematika dan Statistika, I(1), pp. 65-70.

Bowers, N. et al. (1990) Actuarial Mathematics. 2nd edn. The Society of Actuaries. 
Danu Aditya, Johannes Kho, T. P. N. (1980). Premi Asuransi Jiwa Gabungan Berjangka Dengan Asumsi Gompertz. Journal of the Japanese Society of Pediatric Surgeons, 16(4), p. 704.

Fatimah, S., Satyahadewi, N. and Martha, S. (2016). Penentuan Nilai Anuitas Jiwa Seumur Hidup Menggunakan Distribusi Gompertz. Buletin Ilmiah, 05(2).

Kellison, S. G. (2009) The Theory of Interest. 3rd edn. New York: Mc Graw Hill.

Matvejevs, Andrejs and Matvejevs, Aleksandrs (2001). Insurance Models for Joint Life and Last Survivor Benefits. Informatica, 12(4), pp. 547-558.

Promislow, S. D. (2011) Fundamentals of Actuarial Mathematics Second Edition. 2st edn. UK: John Wiley \& SOn Ltd.

Ramadani, K., Dodi, D. and Rahmi, I. (2019). Pengaruh Penggunaan Hukum Mortalitas Gompertz Pada Penentuan Besarnya Asuransi Jiwa Dwiguna dengan Metode Full Preliminary Term. VIII(1), pp. 163-170.

Sertdemir, B. H. (2013) Multiple Life Insurance.

Slud, E. V (2001) 'Actuarial Mathematics and Life-Table Statistics'.

Willemse, W. J. and Koppelaar, H. (2000). Knowledge elicitation of gompertz' law of mortality. Scandinavian Actuarial Journal, 2000(2), pp. 168-179.

Wulan, S., Lestari, R. and Yanita (2017) .Penentuan Premi Asuransi Jiwa Dwiguna Dengan Hukum De Moivre Dan Hukum Gompertz. Jurnal Matematika UNAND, 6(3), p. 112.

Yang, J. and Zhou, S. (2003). Joint-life status and Gompertz's law. pp. 1-10.

Zayanti, D. A., Kresnawati, E. S. and Megah, M. (2019). Joint life insurance based on Gompertz assumptions and interest rate affected by the excange rate. Journal of Physics: Conference Series, 1282(1). 